\title{
Property gradients in oil palm trunk (Elaeis guineensis)
}

\author{
Suthon Srivaro ${ }^{1} \cdot$ Nirundorn Matan ${ }^{1} \cdot$ Frank Lam $^{2}$
}

Received: 12 February 2018 / Accepted: 21 July 2018 / Published online: 4 August 2018

(C) The Japan Wood Research Society 2018

\begin{abstract}
Since the structure of oil palm wood varies dramatically, the property gradients of oil palm wood within a trunk are of great interest. In this study, the physical (density, water uptake and swelling in the radial direction) and mechanical properties (bending modulus of elasticity and strength, compressive modulus of elasticity and strength in the direction parallel to the fiber, compressive strength in the direction perpendicular to the fiber and shear strength in the direction parallel to the fiber) of oil palm wood for a whole trunk were examined. The water uptake, compressive strength in the direction perpendicular to the fiber, shear strength in the direction parallel to the fiber, bending modulus of elasticity and strength and compressive modulus of elasticity and strength in the direction parallel to the fiber appeared to be independent of trunk height but tended to be related to the relative distance from surface or density by a single master curve. However, the swelling in the radial direction of the oil palm wood was not correlated with the relative distance from the surface, trunk height or density. Finally, property map of oil palm wood for a cross section at any height was prepared for practical use.
\end{abstract}

Keywords Oil palm wood $\cdot$ Property gradient $\cdot$ Property map

\section{Introduction}

Oil palm trees (Elaeis guineensis) are commonly planted in tropical zones. A total of the oil palm plantation area found in Southeast Asia is more than half of the global oil palm plantation area [1]. The major product obtained from oil palm tree is crude palm oil, which is generally used in food industries. Oil palm trees are cut down for replanting when they reach approximately $25-30$ years of age because the yield of oil palm fruits becomes relatively low [2]. An enormous amount of oil palm trunk biomass is, therefore, generated, and using this waste product as an alternative

Suthon Srivaro

ssuthon@wu.ac.th; suthon_srivaro@yahoo.com

Nirundorn Matan

mnirundo@wu.ac.th

Frank Lam

frank.lam@ubc.ca

1 Materials Science and Engineering Program, School of Engineering and Resources, Walailak University, Thasala District, Nakhon Si Thammarat 80160, Thailand

2 Department of Wood Science, University of British Columbia, 2424 Main Mall, Vancouver, BC V6T 1Z4, Canada raw material to produce wood and wood based products is of great interest [3-8]. Efficient use of oil palm trunk not only increases its economic value but also mitigates environmental concerns; currently, oil palm biomass is disposed of either by burning or through decomposition by toxic chemicals [6].

Anatomically, the tissue of oil palm wood is made up of two main types of cells, namely fiber and parenchyma cells $[2,3]$. Fiber cells are stiffer and stronger than parenchyma cells $[9,10]$. The distribution of fiber within the oil palm trunk is not uniform, and fiber cells are primarily concentrated around the periphery and then scattered in the central zone $[3,10]$. Generally, cell wall thickness and degree of lignification in palms vary along a cross section and with the trunk height $[9,10]$, and these variations lead to differences in stiffness and strength of the oil palm wood fiber throughout the trunk [10]. Cell wall thickness and degree of lignification are typically highest around the periphery of a cross section and at the bottom of the trunk [10].

Most of the physical and mechanical properties of oil palm wood are determined by the fiber cells $[3,10,11]$. Due to variations in the characteristics of the fiber cells and their distribution in the oil palm wood tissue, substantial variations in the physical and mechanical properties of oil palm wood have been observed [3,10-14]. These variations make 
the practical use of oil palm wood difficult. For example, in the primary processing of oil palm wood, the sawing, chemical treatment and drying processes are complicated by the fact that woods with different characteristics need different treatments [15]. In addition, without a practical understanding of the properties of oil palm wood for specific applications, it is difficult to work with. Thus, precise property classifications of oil palm wood are needed to increase the practical applications of this material.

The aim of this research is to investigate the gradients in the physical and mechanical properties of oil palm wood at various positions along cross sections and at different trunk heights. Based on this information, property map of oil palm wood was then developed for practical use.

\section{Materials and methods}

\section{Materials}

A 25-year-old oil palm tree was felled from a plantation in the Thasala district, Nakhon Si Thammarat Province, Thailand. The height of the trunk was approximately $7.5 \mathrm{~m}$. The entire trunk was cross cut to obtain 1-m-long logs. A total of seven $\operatorname{logs}$ were obtained. Diameter of the logs ranged from $31 \mathrm{~cm}$ to $48 \mathrm{~cm}$. These $\log$ s were converted into lumber with the dimensions of $3 \mathrm{~cm}$ (radial) $\times 10 \mathrm{~cm}$ (tangential) $\times 100 \mathrm{~cm}$ (longitudinal) using a circular saw. The position of each piece of lumber with respect to the center of the cross section ( $r$ ) was recorded. The lumber was dried at dry-bulb and wet-bulb temperatures of 50 and $40{ }^{\circ} \mathrm{C}$, respectively, to final moisture contents of $12 \%$ using the laboratory kiln at the Research Center of Excellence on Wood Science and Engineering, School of Engineering and Resources, Walailak University, Thailand. After drying, the dimension lumber obtained from oil palm wood at trunk heights above $5 \mathrm{~m}$ had severe drying defects and, therefore, could not be utilized in this study. Thus, the samples from below that trunk height were used for preparation of the test specimens. The test specimens were prepared according to ASTM D 143 [16] with some modifications to determine the density, water uptake, swelling in the radial direction, bending and compression properties of the oil palm wood. The dimensions of the specimens used for the density, water uptake, swelling in the radial direction, compressive strength in the direction perpendicular to the fiber and compressive modulus of elasticity and strength in the direction parallel to the fiber tests were approximately $1.5 \mathrm{~cm}(\mathrm{R}) \times 1.5 \mathrm{~cm}$ $(\mathrm{T}) \times 4.5 \mathrm{~cm}(\mathrm{~L})$. The dimensions of the specimens used for shear strength in the direction parallel to the fiber were approximately $1.5 \mathrm{~cm}(\mathrm{R}) \times 1.5 \mathrm{~cm}(\mathrm{~T}) \times 1.5 \mathrm{~cm}(\mathrm{~L})$. The dimensions of the specimens for the bending tests were approximately $1.5 \mathrm{~cm}(\mathrm{R}) \times 1.5 \mathrm{~cm}(\mathrm{~T}) \times 32 \mathrm{~cm}(\mathrm{~L})$. Before testing, all specimens were kept in a conditioning room at $20{ }^{\circ} \mathrm{C}$ and $65 \%$ humidity for 1 month.

\section{Physical property testing}

\section{Density}

The weight $(m)$ and volume $(V)$ of specimens at $12 \%$ moisture content were measured. The density $(\rho)$ of each specimen at $12 \%$ moisture content was then calculated using the following equation:

$\rho=\frac{m}{V}$.

Water uptake (WU) and swelling in the radial direction (SR)

The weight $(m)$ and dimensions of the specimens at $12 \%$ moisture content were measured before and after soaking in distilled water at $20^{\circ} \mathrm{C}$ for $24 \mathrm{~h}$. WU and SR were then calculated using the following equations:

$\mathrm{WU}(\%)=\frac{W_{\text {after }}-W_{\text {before }}}{W_{\text {before }}} \times 100$,

$\mathrm{SR}(\%)=\frac{R_{\mathrm{after}}-R_{\text {before }}}{R_{\text {before }}} \times 100$,

where $W_{\text {after }}$ is the weight of the specimen after being soaked in water, $W_{\text {before }}$ is the weight of the specimen before being soaked in water, $R_{\text {after }}$ is the dimension of the specimen in the radial direction after being soaked in water and $R_{\text {before }}$ is the dimension of the specimen in the radial direction before being soaked in water.

\section{Mechanical property testing}

The mechanical property tests were conducted using a universal testing machine (Lloy, UK) under displacement control mode based on crosshead movement. The measured values were automatically calculated and recorded by the computer which was directly connected to the testing machine during the test.

\section{Bending properties}

Three-point bending tests were conducted to determine the bending properties of oil palm wood. The specimens were placed on the two supporting rollers and loaded at the midspan length with a crosshead speed of $10 \mathrm{~mm} / \mathrm{min}$ until fracture (Fig. 1). A span length to thickness ratio of 20 was used for the entire test. The bending moduli of elasticity (MOE) and strength (or modulus of rupture, MOR) were then calculated using the following equations: 


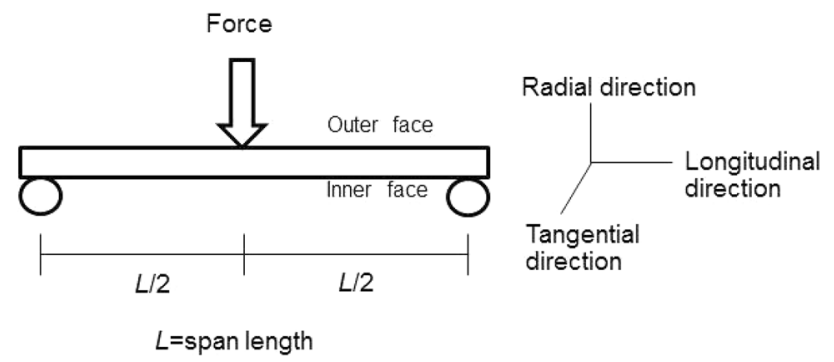

Fig. 1 Experimental setup for three-point bending test of oil palm wood samples

$\mathrm{MOR}=\frac{3 P_{\max } L}{2 b d^{2}}$

$\mathrm{MOE}=\frac{L^{3}}{4 b d^{3}}(P / \delta)_{\mathrm{PL}}$,

where $P_{\max }$ is the maximum load, $L$ is the span length, $b$ is the width of the specimen (dimension in the tangential direction), $d$ is the thickness of the specimen (dimension in the radial direction) and $(P / \delta)_{\mathrm{PL}}$ is the slope within linear region of load-displacement curve. The inner face was positioned to be subjected to tensile stresses under bending to achieve more conservative results as the inner face is assumed to be weaker than the outer face.

\section{Compression in the direction parallel to the fiber}

The specimens were loaded parallel to the direction of the fiber with a crosshead speed of $2 \mathrm{~mm} / \mathrm{min}$ until fracture. The compressive moduli of elasticity $\left(E_{/ /}\right)$and strength $\left(\sigma_{/ /}\right)$in the direction parallel to the fiber were then calculated using the following equations:

$\sigma_{/ /}=\frac{P_{\max }}{A}$,

$E_{/ /}=\frac{h}{A}(P / \delta)_{\mathrm{PL}}$,

where $P_{\max }$ is the maximum load, $A$ is the area of the cross section, $h$ is the height of the specimen (dimension in the longitudinal direction), $(P / \delta)_{\mathrm{PL}}$ is the slope within linear region of load-displacement curve.

\section{Compressive strength in the direction perpendicular to the fiber $\left(\sigma_{\perp}\right)$}

The oil palm wood specimen was loaded in the direction perpendicular to the fiber at mid-section through steel plate of 2 $\mathrm{cm} \times 2 \mathrm{~cm}$ in dimension with a crosshead speed of $2 \mathrm{~mm} / \mathrm{min}$ until the deformation of $2.5 \mathrm{~mm}$ was reached. Compressive strength in the direction perpendicular to the fiber $\left(\sigma_{\perp}\right)$ was then calculated using the following equation:

$\sigma_{\perp}=\frac{P_{\mathrm{PL}}}{A_{\mathrm{b}}}$,

where $P_{\mathrm{PL}}$ is load at proportional limit and $A_{\mathrm{b}}$ is load-bearing area.

\section{Shear strength in the direction parallel to the fiber}

The oil palm wood specimen was loaded on tangential-longitudinal plane with a crosshead speed of $2 \mathrm{~mm} / \mathrm{min}$ until fracture. The maximum shear force $(V)$ was then taken to calculate shear strength in the direction parallel to the fiber $\left(\tau_{/ l}\right)$ using the following equation:

$\tau_{/ /}=\frac{V}{A_{\mathrm{s}}}$,

where $A_{\mathrm{s}}$ is shear area on tangential-longitudinal plane.

\section{Results and discussion}

The various regression relationships of the examined properties of oil palm wood, including both linear and nonlinear relationships, with their associated $R$-squared $\left(R^{2}\right)$ and error sum of squares (SSE) are shown in Table 1. The power law relationship seemed to give a better goodness of the fit for all cases, showing similar or higher $R^{2}$ and lower SSE compared with ones obtained from linear relationship. However, in case of MOE-density relationship, SSE obtained from power law relationship appeared to be slightly higher but also higher $R^{2}$. Therefore, in this study, power law relationship was used to plot all experimental results.

\section{Physical properties}

\section{Density}

The plot of the densities of oil palm wood compared to their relative distance from the surface (the position of each specimen with respect to periphery of the cross section $(R-r)$ divided by the corresponding radius of the cross section $(R)$ where the specimen was taken from the trunk) at various trunk heights is shown in Fig. 2. The density of oil palm wood at any trunk height decreased from the periphery to the central zone of the cross section, and the densities ranged from $222 \mathrm{~kg} / \mathrm{m}^{3}$ to $404 \mathrm{~kg} / \mathrm{m}^{3}$. Basically, vascular bundles (fibers, phloem, xylem) in oil palm wood tissue congests in periphery zone (approximately 30\%) and gradually decreases to the central zone (approximately 14\%) 


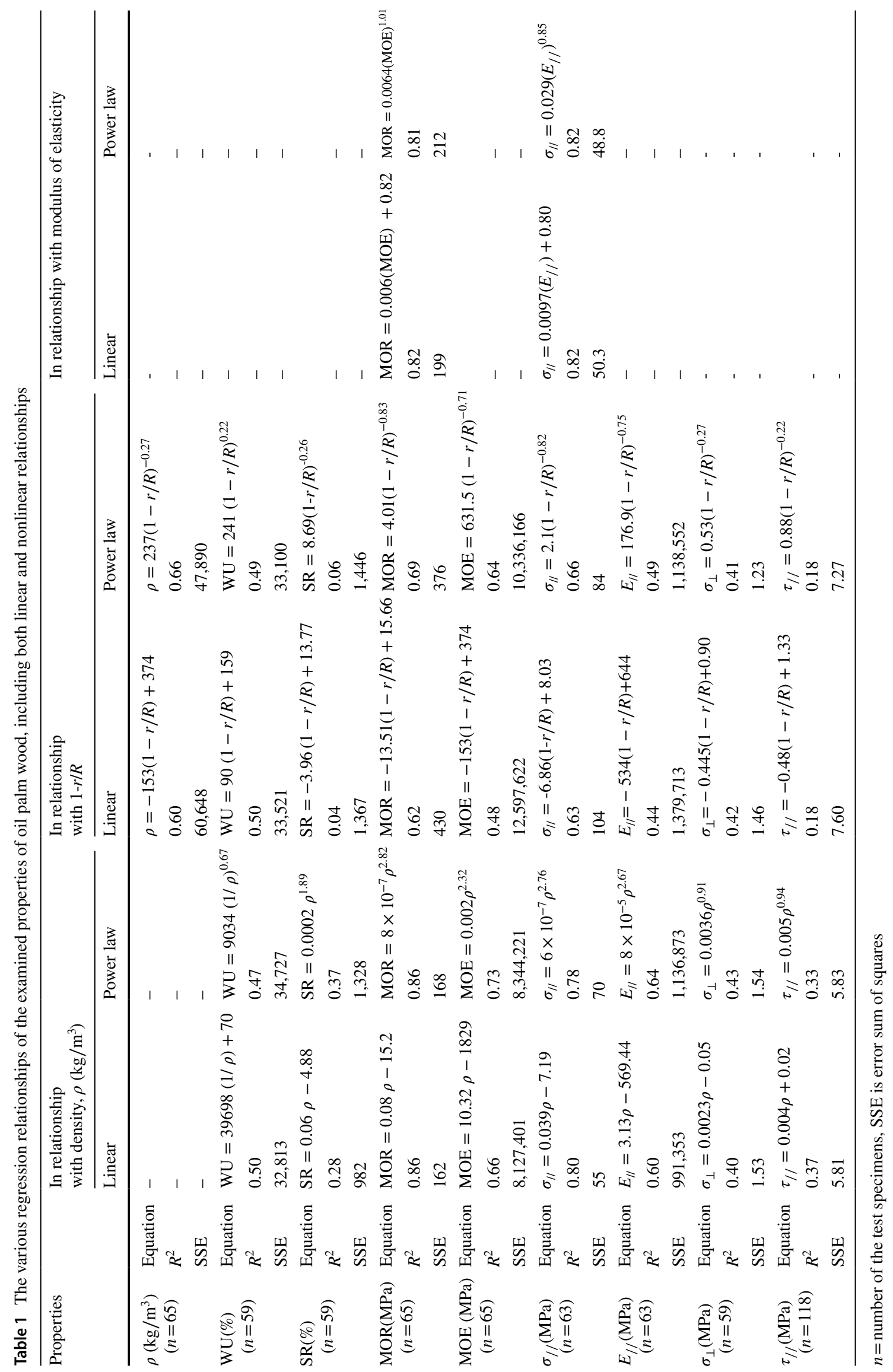




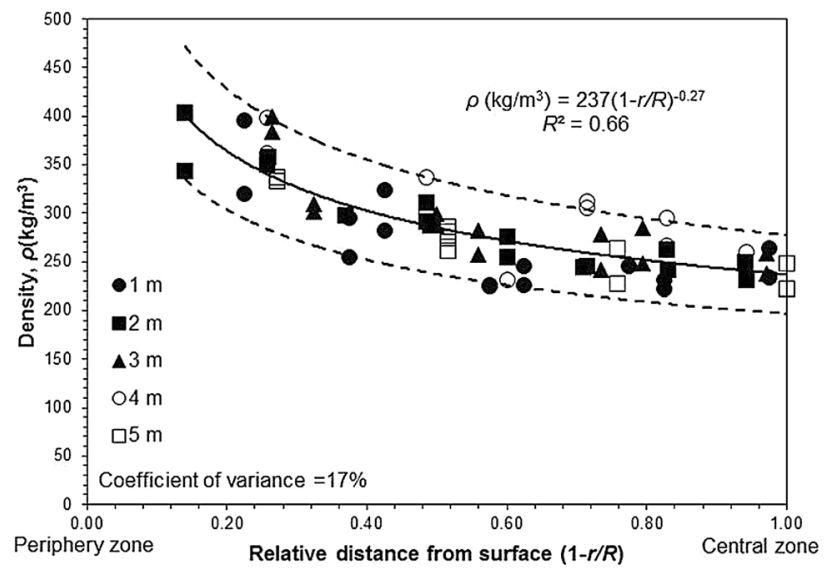

Fig. 2 Density ( $\rho$ ) of oil palm wood at various positions along a cross section and at different trunk heights plotted against their relative distances from the surface $(1-r / R)$

[10]. Fiber is the determining factor in the density of oil palm wood [3, 9-11]. Thus, the density of oil palm wood should be lower in the central zone compared to the outer zone because the fiber content in the central zone is lower $[3,10]$. The trend observed here corresponds to that of other palm species reported elsewhere [9]. However, it was noticed that the maximum oil palm wood density obtained from this study was lower than the ones reported in the literature $[17,18]$. This might be resulting from differences in plantation area, age of oil palm trunk and position of the test specimen within the trunk. In addition, drying schedule used for drying process of oil palm wood specimens might also affect the density of oil palm wood. Using more severe drying schedule could affect parenchyma cells to collapse, resulting in increased oil palm wood density because the void volume in wood tissue had decreased.

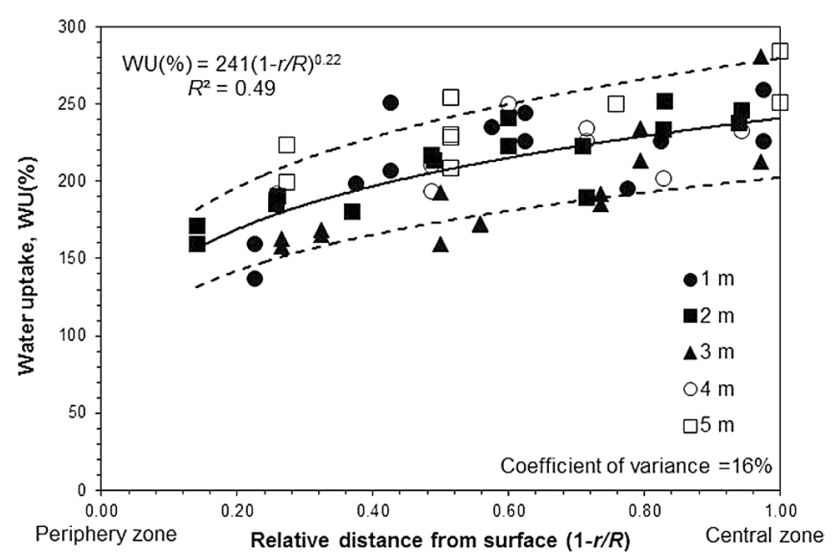

Fig. 3 Water uptake (WU) of oil palm wood at various positions along a cross section and at different trunk heights plotted against their relative distances from the surface $(1-r / R)$

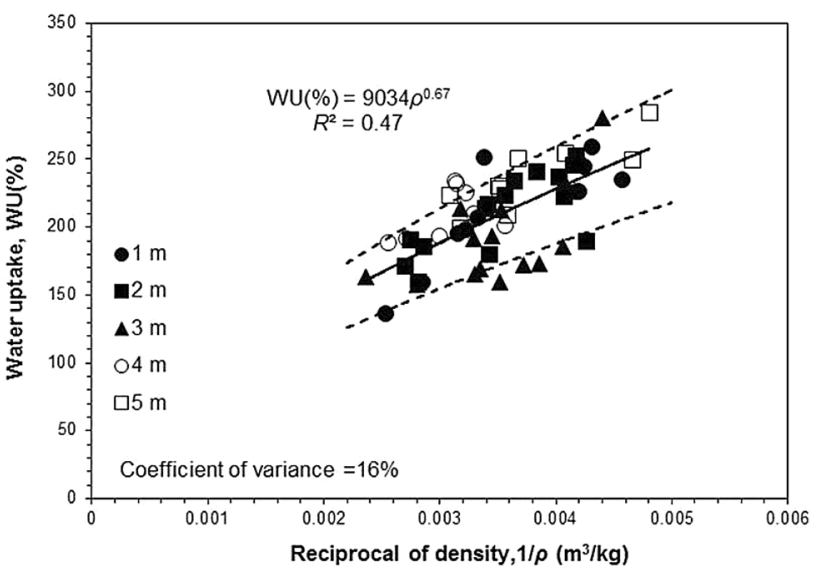

Fig. 4 Water uptake (WU) of oil palm wood at various positions along a cross section and at different trunk heights plotted against density $(\rho)$

In addition, the densities of oil palm wood for all the trunk heights fall into a single master curve with respect to the relative distance from the surface. As seen in Fig. 2, at a given relative distance from the surface, the densities of oil palm wood at any trunk height were similar. The calculated coefficient of variance of the mean density values at various relative distances from the surface was approximately $17 \%$. This value was higher than the coefficient of variance of the specific gravity of typical softwoods and hardwoods, which is approximately $10 \%$ [19].

\section{Water uptake (WU)}

The plot of the water uptake capacities of oil palm wood specimens at various trunk heights against their relative distances from the surface is shown in Fig. 3. The WU of

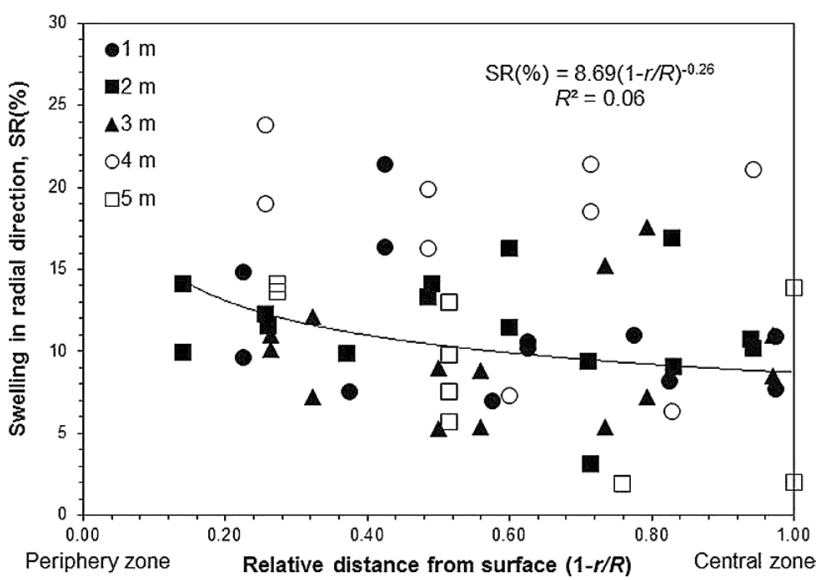

Fig. 5 Swelling in the radial direction (SR) of oil palm wood at various positions along a cross section and at different trunk heights plotted against their relative distances from the surface $(1-r / R)$ 


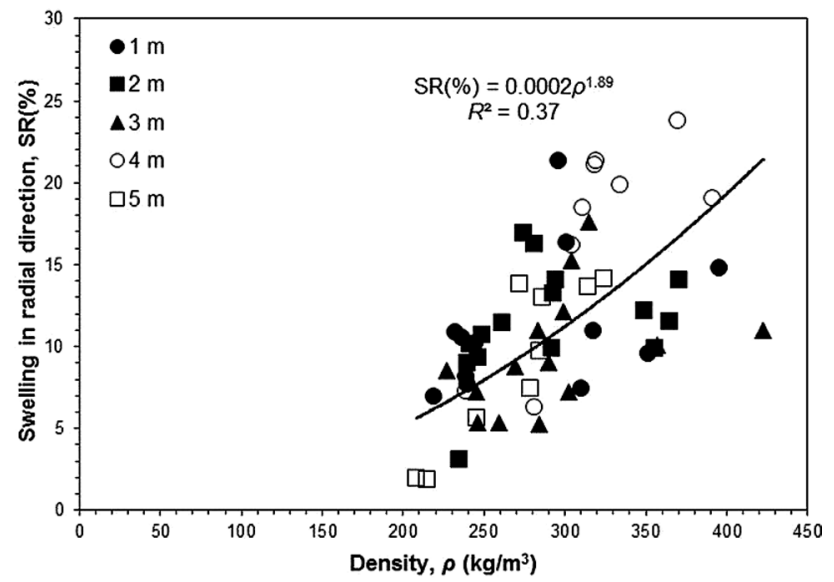

Fig. 6 Swelling in the radial direction (SR) of oil palm wood at various positions along a cross section and at different trunk heights plotted against density $(\rho)$

oil palm wood decreased from the periphery to the central zones for all tested trunk heights because the central zone contains a greater fraction of thin-walled parenchyma cells $[3,10]$, which provide many more cavities that can be filled with water compared to thick-walled fiber cells $[3,10]$. In addition, higher content of starch, which could also retain water in oil palm wood tissue, in central zone [20], might also contribute to higher WU value of oil palm wood in central zone. It should also be noticed that the WU values of oil palm wood samples from all tested trunk heights fell along a single master curve with respect to their relative distance from surface (Fig. 3). The calculated coefficient of variance of the mean WU value at various relative distances from the surface was approximately $16 \%$. In addition, the WU of oil palm wood was directly proportional to the reciprocal of wood density regardless of the position of the wood specimen within the trunk (Fig. 4). This value for typical woods is strongly dependent on the presence of cavities in the wood tissue, which is inversely proportional to the wood density [21]. Thus, the WU capacities of lower density oil palm wood should be higher due to more cavities that can be filled with water.

\section{Swelling in the radial direction (SR)}

The plot of swelling in the radial direction of the oil palm wood for all trunk heights against the relative distance of the sample from the surface is shown in Fig. 5. The SR of oil palm wood varied substantially, and no correlation between the experimental SR values and the relative distance from the surface was observed. The values of SR ranged from 1.9 to $23.8 \%$. Figure 6 shows the relationship between the experimental SR data against oil palm wood density which seems to be fairly weak $\left(R^{2}=0.37\right.$ and $\left.\mathrm{SSE}=1,328\right)$. Generally, SR

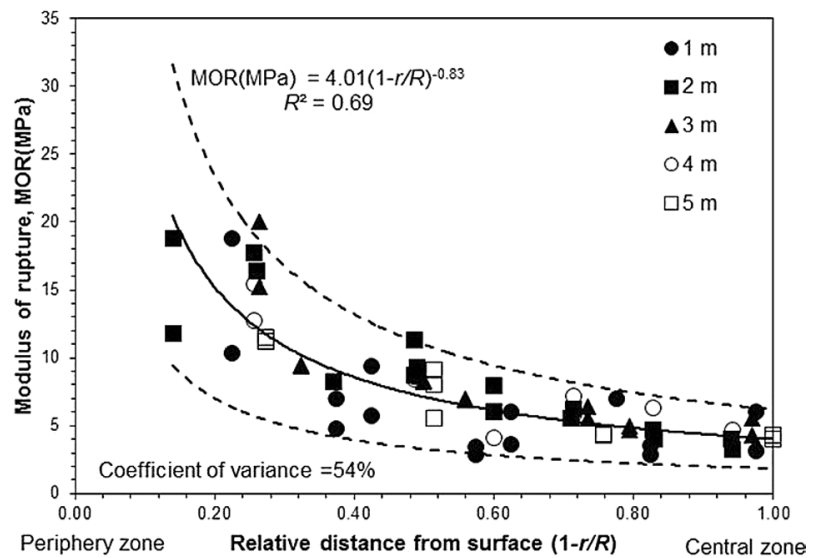

(a)

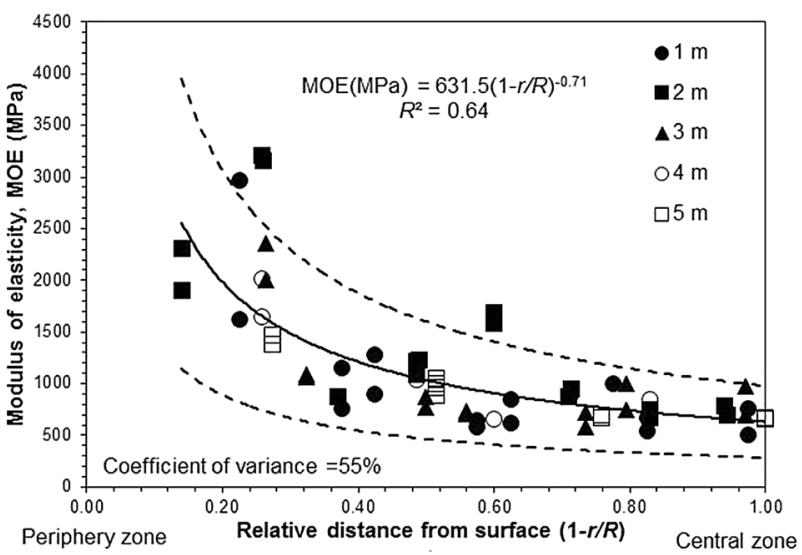

(b)

Fig. 7 Bending properties of oil palm wood at various positions along a cross section and at different trunk heights plotted against their relative distances from the surface $(1-r / R)$; a modulus of rupture (MOR) and $\mathbf{b}$ modulus of elasticity (MOE)

for typical softwoods and hardwoods increases with wood density [22]. This is because higher density woods have thicker cell walls and, therefore, they tend to swell more compared to lower density wood. However, in the case of oil palm wood, the swelling mechanism might be different from that of typical woods because oil palm wood tissue consists of two different types of cells (fiber and parenchyma cells). These cells have different cell wall thicknesses as indicated by easy collapse of the thin-walled parenchyma cells during drying $[6,12]$. The increase in volume of oil palm wood during the thickness swell experiments might not only be contributed by swelling of wood cell wall but also an increase in volume of water-filled cell cavity during soaking in water. Furthermore, it might also be possible that the drying/swelling response of parenchyma cells might be dependent on its location along trunk heights because wood cells are younger at the top part of the trunk $[3,10]$. This might be the reason for weak relationship of swelling of oil palm wood tissue with either relative distance from 


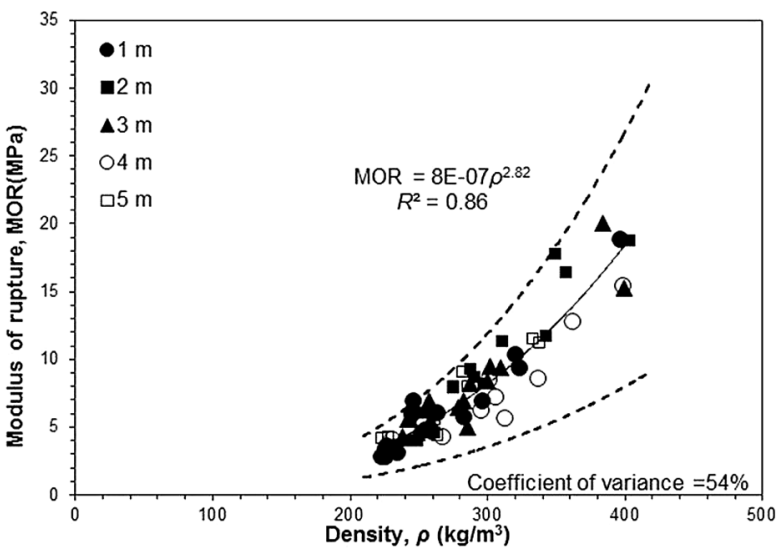

(a)

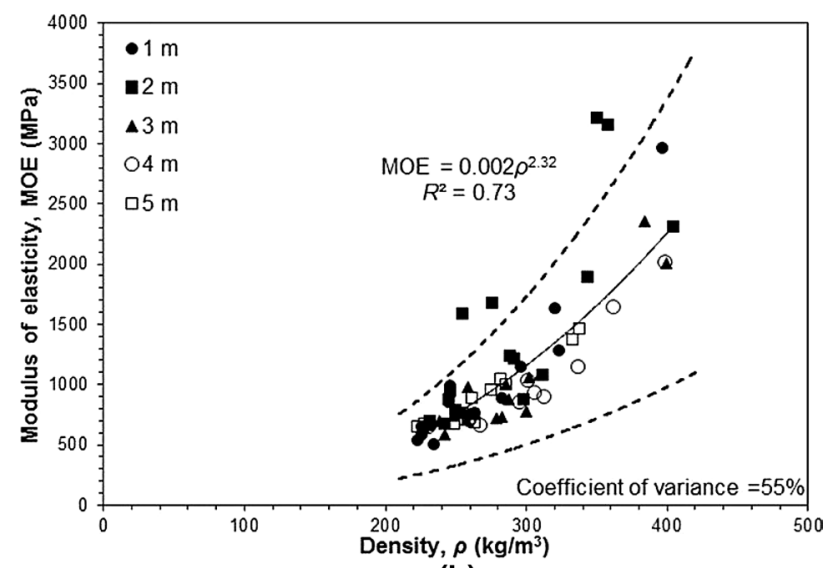

(b)

Fig. 8 Bending properties of oil palm wood at various positions along a cross section and at different trunk heights plotted against density $(\rho)$; a modulus of rupture (MOR) and $\mathbf{b}$ modulus of elasticity (MOE)

surface or density. However, this hypothesis requires further exploration.

\section{Mechanical properties}

\section{Bending properties}

The plot of MOE and MOR of the oil palm wood samples from all the tested trunk heights compared to their relative distances from the surface is shown in Fig. 7. The values of both parameters for oil palm wood samples for all tested trunk heights increased from the central to the periphery zones within a cross section because the fiber contents are higher in the periphery zones [3,10]. This trend is consistent with those reported elsewhere for other palm species [23]. All experimental data seemed to fall into a single master curve with respect to the relative distance from the surface for all tested trunk heights. As seen in Fig. 7, at a given relative distance from the surface, the MOE and MOR of the oil palm wood samples from all tested trunk heights were

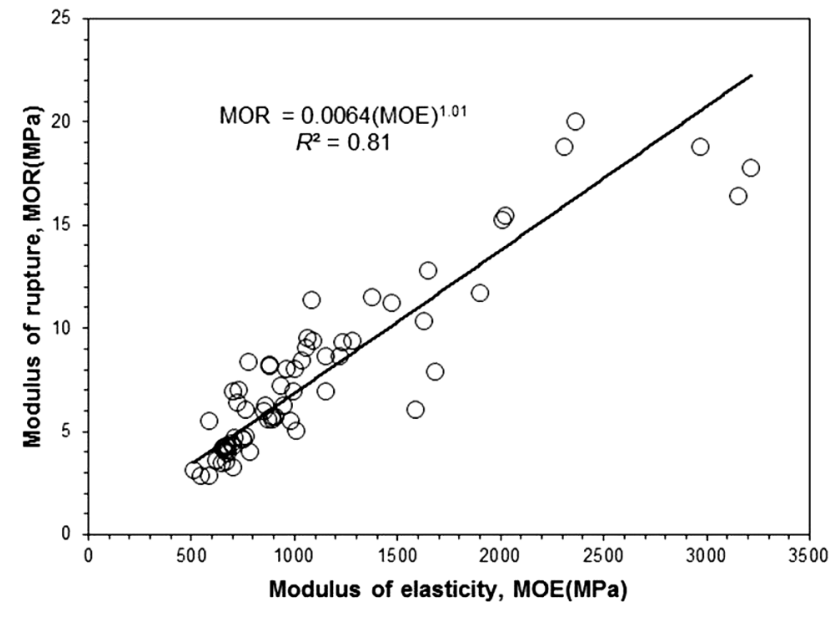

Fig. 9 Relationship between modulus of rupture and modulus of elasticity of oil palm wood

similar. The calculated coefficients of variance of the mean MOE and MOR values were approximately 55 and 54\%, respectively. These values were higher than those of typical woods, which are approximately 16 and $22 \%$, respectively [19]. These results indicate that the variations in the values of the MOE and MOR of oil palm wood are greater than the variations seen in other woods.

The plot of the MOE and MOR of the oil palm wood samples compared to their density is given in Fig. 8. The values of both parameters increased with increasing density because the fiber content is higher in a higher density wood $[3,10,11,23]$. In addition, all experimental data appeared to fall along a single master curve with respect to density. The stiffness and strength of oil palm wood fiber have been reported to vary depending on the position along the cross section and trunk height [10]. However, the results in this study indicate that the values of MOR and MOE of oil palm wood were strongly related to the apparent density regardless of the position of the wood sample within the trunk. The relationship between each of these values and the density of the samples followed power law equations with similar exponents (2.82 and 2.32, respectively). The trend of this result was similar to those reported elsewhere for other palm species [23]. Rich [23] examined six palm species and reported that the MOR and MOE of all palm species examined were related to their dry densities by power law relationships with similar exponents (2.05 and 2.45 , respectively) to those of the oil palm species studied herein.

Figure 9 shows the relationship between MOR and MOE of oil palm wood which seems to be very strong, showing relatively high $R^{2}(0.81)$ and low SSE (212). Typically, the $R^{2}$ of 0.5 is observed for softwoods; i.e., $50 \%$ variation in the strengths can be explained by MOE as a non-destructive prediction parameter. It might be possible that the large range of MOE values of oil palm wood could improve $R^{2}$. 


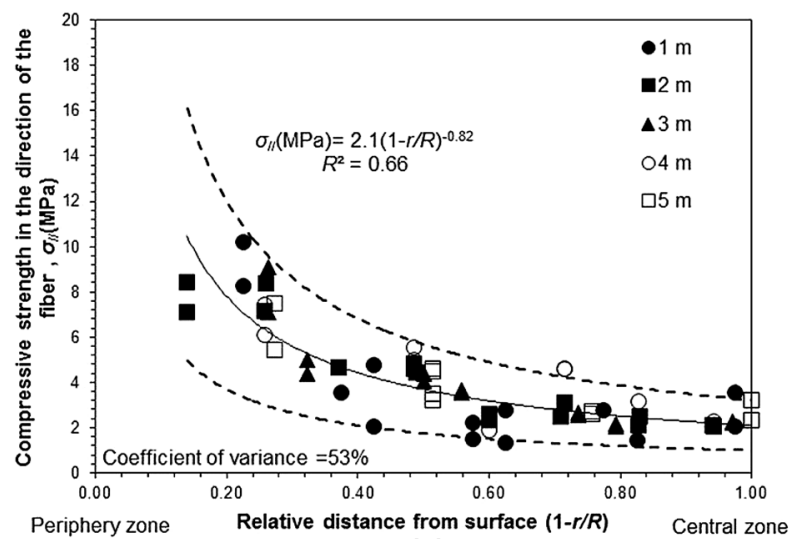

(a)

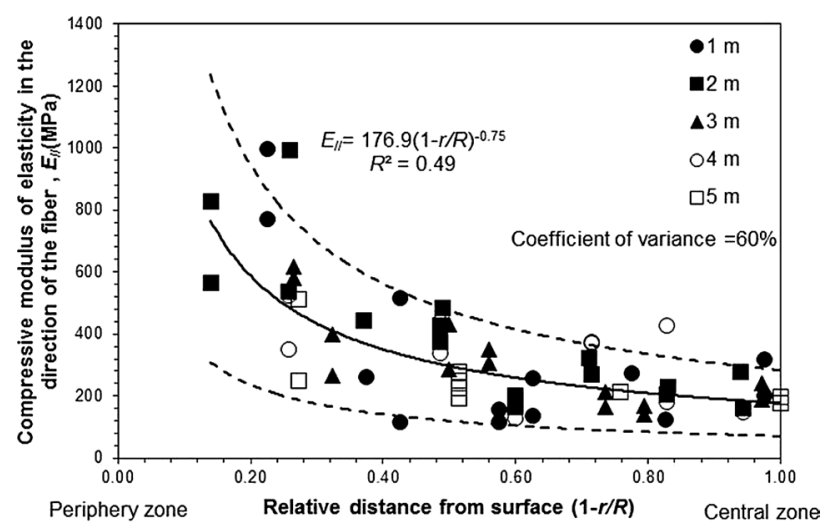

(b)

Fig. 10 Compressive properties in the direction of the fiber of oil palm wood at various positions along a cross section and at different trunk heights plotted against their relative distance from the surface $(1-r / R)$; a compressive strength $\left(\sigma_{\| /}\right)$and $\mathbf{b}$ compressive modulus of elasticity $\left(E_{/ /}\right)$

\section{Compressive properties in the direction parallel to the fiber}

The plot of $E_{/ /}$and $\sigma_{/ /}$of the oil palm wood for all tested trunk heights compared to their relative distance from the surface is shown in Fig. 10. The values of both parameters for oil palm wood increased from the central to periphery zones within a cross section because, as mentioned above, the fiber content in the periphery zone is higher. The values ranged from 1.3 to $10.2 \mathrm{MPa}$ for $\sigma_{/ /}$and $114-996 \mathrm{MPa}$ for $E_{/ /}$. In addition, all experimental data fell along a single master curve with respect to their relative distance from the surface (Fig. 10). The calculated coefficients of variance of the mean values of the $E_{/ /}$and $\sigma_{/ /}$at various relative distances from surface were approximately 60 and $53 \%$, respectively. These values were approximately 3.0-3.3 times higher than those of typical softwoods and hardwoods, which are approximately $18 \%$ [19].

Figure 11 shows the plot of the $\sigma_{/ /}$and $E_{/ /}$relative to density, and both of these parameters increased with increasing

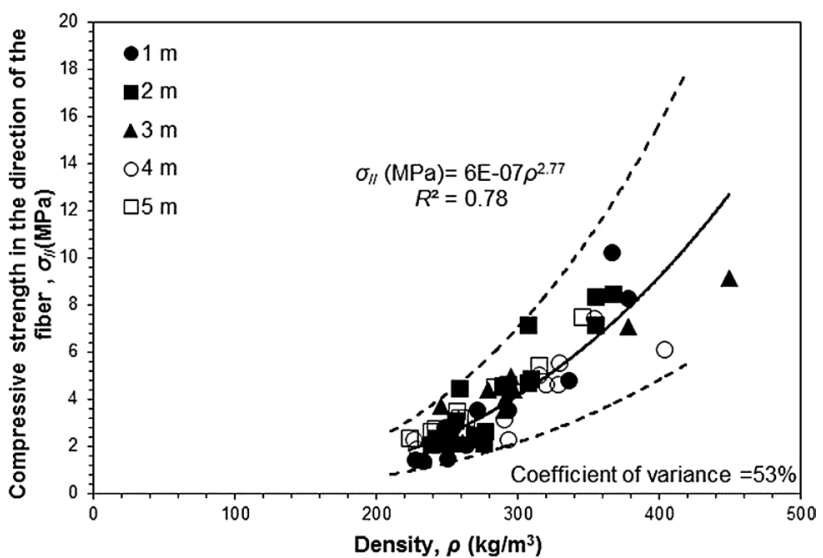

(a)

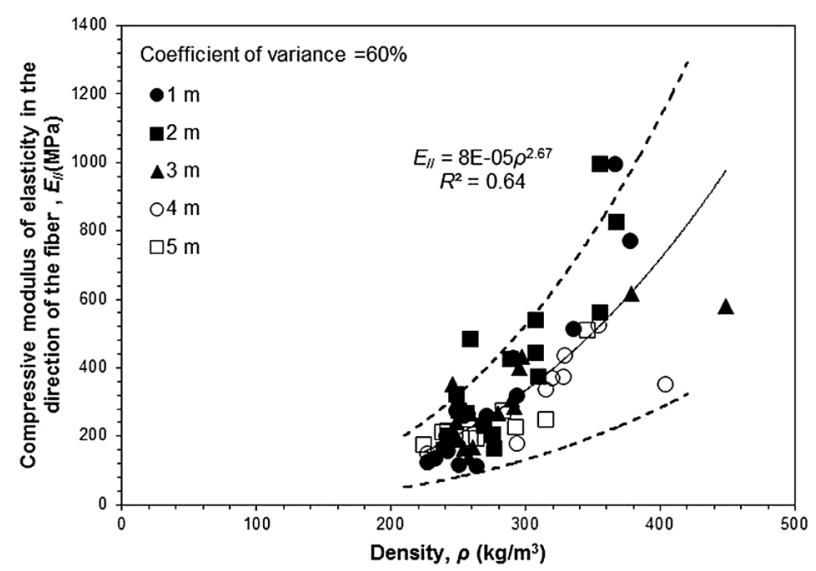

(b)

Fig. 11 Compressive properties in the direction of the fiber of oil palm wood at various positions along a cross section and at different trunk heights plotted against density $(\rho)$; a compressive strength $\left(\sigma_{/ /}\right)$ and $\mathbf{b}$ compressive modulus of elasticity $\left(E_{/ /}\right)$

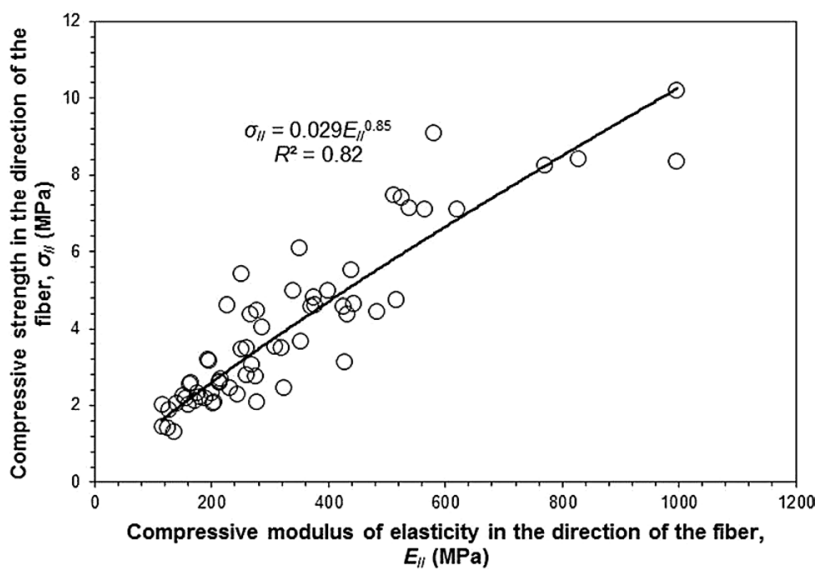

Fig. 12 Relationship between compressive strength and modulus of elasticity in the direction of the fiber of oil palm wood 


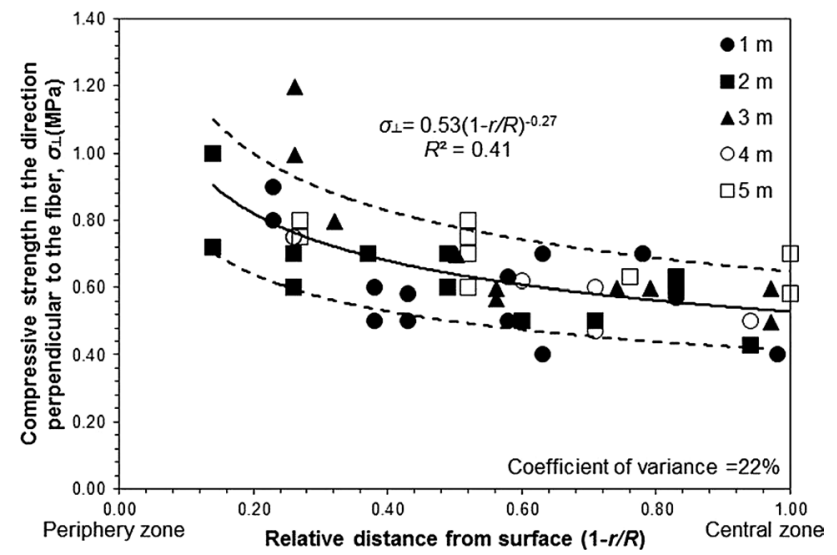

Fig. 13 Compressive strength in the direction perpendicular to the fiber $\left(\sigma_{\perp}\right)$ of oil palm wood at various positions along a cross section and at different trunk heights plotted against their relative distances from the surface $(1-r / R)$

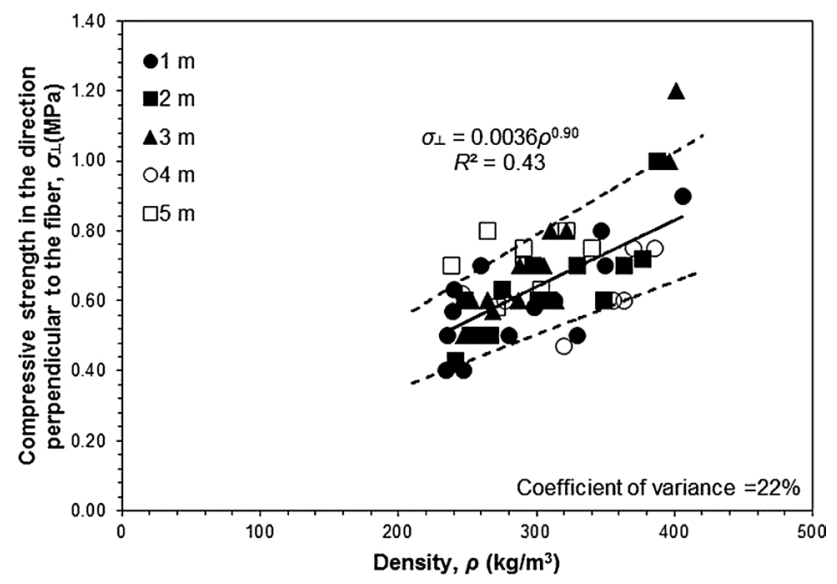

Fig. 14 Compressive strength in the direction perpendicular to the fiber $\left(\sigma_{\perp}\right)$ of oil palm wood at various positions along a cross section and at different trunk heights plotted against density $(\rho)$

density because higher density woods have higher fiber contents. Moreover, both parameters seemed to be strongly related to the density of the oil palm wood regardless of the position of the wood sample within the trunk. As seen in Fig. 11, the experimental values of the $\sigma_{/ /}$and $E_{/ /}$of the oil palm wood at all tested trunk heights fell along a single master curve with respect to density. The values of both parameters and density were related by power law equations. The exponents for $E_{/ /}$and $\sigma_{/ /}$were approximately 2.67 and 2.76 , respectively. Notably, these exponents were similar to those of MOE and MOR. Figure 12 shows that the $\sigma_{/ /}$seemed to be strongly related to $E_{/ /}$, showing relatively high $R^{2}(0.82)$ and low SSE (48.8). This indicates that $\sigma_{/ /}$could be predicted

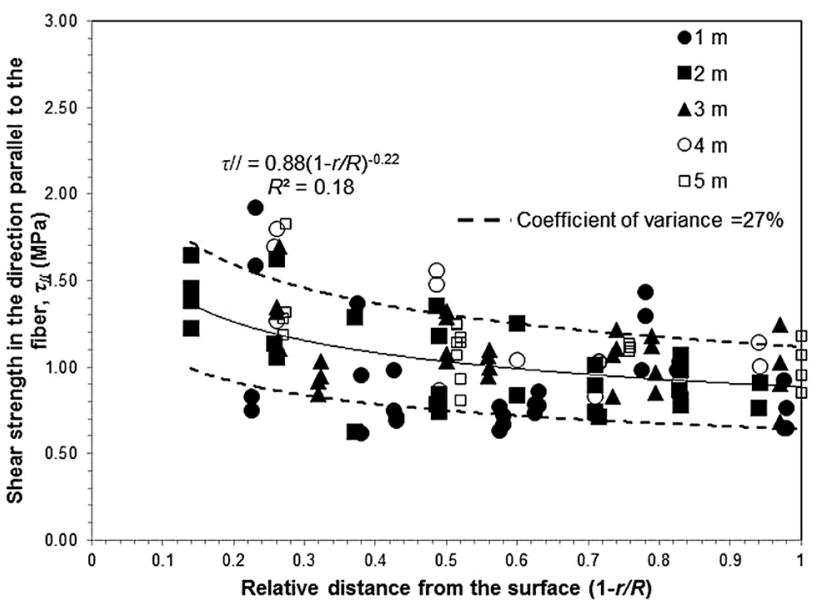

Fig. 15 Shear strength in the direction parallel to the fiber $\left(\tau_{/ /}\right)$of oil palm wood at various positions along a cross section and at different trunk heights plotted against their relative distances from the surface $(1-r / R)$

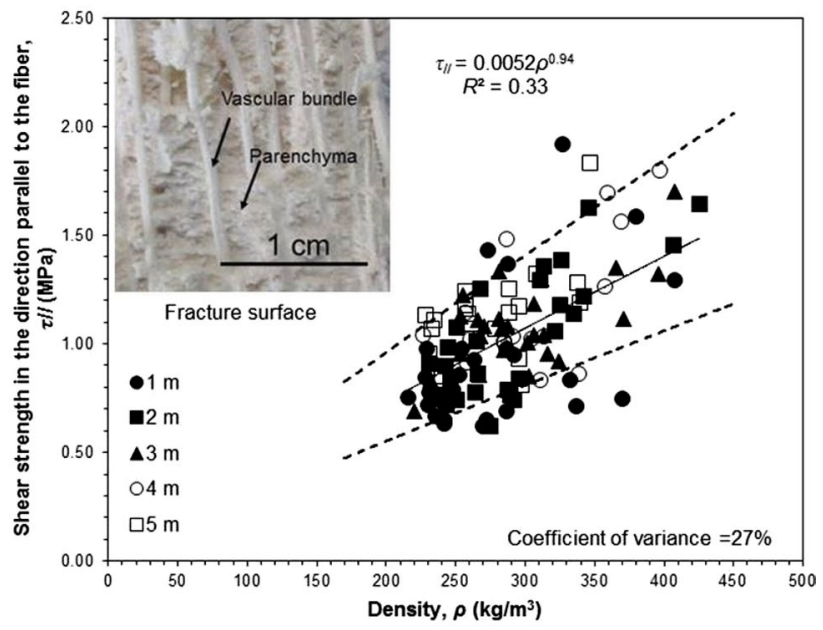

Fig. 16 Shear strength in the direction parallel to the fiber $\left(\tau_{/ /}\right)$of oil palm wood at various positions along a cross section and at different trunk heights plotted against density $(\rho)$

from the known $E_{/ /}$value, which would be useful for strength grading and design of oil palm wood in practice.

Moreover, it was also observed that at a given density, the $E_{/ /}$and $\sigma_{/ /}$of the oil palm wood were approximately 0.3 and 0.5 times of the MOE and MOR, respectively. The $\sigma_{/ /} /$ MOR ratio of oil palm wood was similar to those of typical softwoods and hardwoods, which are approximately 0.56 for clear wood specimens [19]. The ratio between the $E_{/ /} / \mathrm{MOE}$ of oil palm wood (0.3) was lower than those of typical softwoods, which are approximately 0.96-1.23 [24]. Moreover, the modulus and strength under compressive and bending loads of oil palm wood were lower than those of typical softwoods and hardwoods with the same densities [19]. 


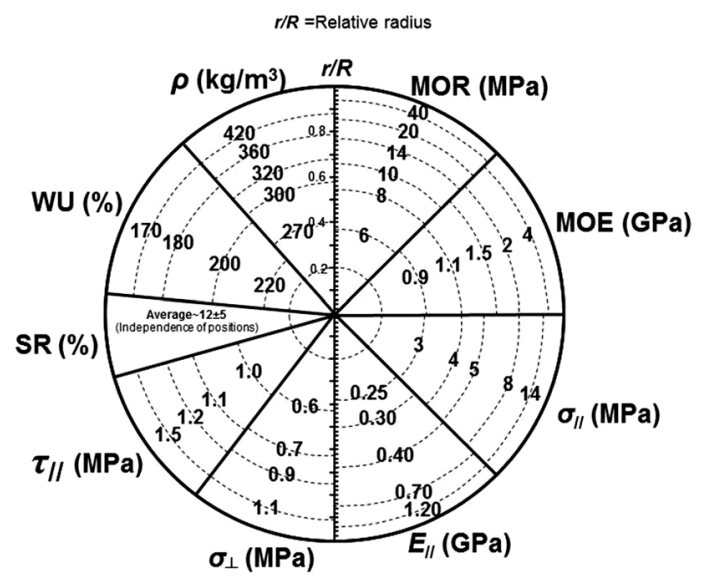

Fig. 17 Property map of oil palm trunk at any cross section of the trunk

\section{Compressive strength in the direction perpendicular to the fiber $(\sigma \perp)$}

Compressive strength in the direction perpendicular to the fiber of oil palm wood at all tested trunk heights plotted against relative distance from the surface is shown in Fig. 13. The result showed that $\sigma_{\perp}$ value of oil palm wood appeared to increase from periphery to central zone, but small gradient (the values ranged from 0.4 to $1.2 \mathrm{MPa}$ ). Moreover, it was found that experimental data for all tested trunk heights are related to relative distance from the surface $(1-r / R)$ by a single master curve. The calculated coefficient of variance of the mean value was about $26 \%$. This value is slightly lower than that of typical wood which was reported to be about 28\% [19]. In addition, it was also found that $\sigma_{\perp}$ value of oil palm wood appeared to increase with density by a single master curve (Fig. 14). Higher fraction of fiber might contribute to increase load carrying capacity of higher density wood.

\section{Shear strength in the direction parallel to the fiber $\left(\tau_{/ /}\right)$}

Shear strengths in the direction parallel to the fiber of oil palm wood at all tested trunk heights plotted against relative distance from the surface is shown in Fig. 15. The result showed that $\tau_{\| /}$value seemed to slightly decrease from periphery to central zone for all tested trunk heights but correlation between $\tau_{/ /}$value and relative distance from the surface was poor as can be seen in Fig. 15. The calculated coefficient of variance of the mean value was about $27 \%$ which is two times greater than that of typical wood [19]. Plotting $\tau_{/ /}$value against density, it was found that $\tau_{/ /}$value seemed to increase with density (Fig. 16). However, the correlation between both values was poor, showing $R^{2}$ value of 0.33 . Examination of fracture surface of oil palm wood specimen revealed that parenchyma cell tore away due to shear force while vascular bundles still stick on to the ground tissue (Fig. 16). This indicates that shear strength parallel to the direction of fiber of oil palm wood is governed by parenchyma cell characteristic. The lower shear strength may arise as a result of lower degree of lignification of parenchyma cell in central zone or lower density wood [3].

\section{Property map for oil palm trunk}

Notably, a number of properties vary with relative distance from the surface $(1-r / R)$ but are independent of height, so a property map can be developed. Figure 17 shows the various properties of oil palm trunk for any cross sections with respect to the relative radius $(r / R)$. The dashed lines in each figure represent the wood samples with the same property. The density and strength of oil palm wood increase while WU decreases moving from the central to periphery zones. These maps could facilitate the practical grading of oil palm wood properties. However, the effects of other potential parameters that may impact the properties of oil palm wood, such as age, the variation between the different trunk, species and plantation area of oil palm tree and drying condition should be explored to increase the precision of these maps.

\section{Conclusions}

The following conclusions can be drawn from this study.

1. Density, shear strength in the direction parallel to the fiber, compressive strength in the direction perpendicular to the fiber, bending modulus of elasticity and strength and compressive modulus of elasticity and strength in the direction parallel to the fiber for all tested trunk heights increased whereas WU decreased moving from the central to the outer zones within a cross section.

2. Water uptake, shear strength in the direction parallel to the fiber, compressive strength in the direction perpendicular to the fiber, bending modulus of elasticity and strength and compressive modulus of elasticity and strength in the direction parallel to the fiber for all tested trunk heights appeared to be related to the relative distance from the surface or density by a single master curve regardless of the position of the wood within the trunk.

3. Swelling in the radial direction of the oil palm wood was not related to the position within the trunk or density.

4. Property map of oil palm wood was prepared to facilitate the determination of required wood properties. 
Acknowledgements This work was supported by the Thailand Research Fund through the Royal Golden Jubilee Advanced Programme (Contract no. RAP60K0017). The authors would also like to thank the Research Center of Excellent on Wood Science and Engineering, School of Engineering and Resources, Walailak University, Thailand, for providing facilities for experimental work. The authors declare that they have no conflict of interest.

\section{References}

1. FAO (2017) FAOSTAT Online statistical service. Available from:http://www.fao.org/faostat Accessed 7 November 2017

2. Hartley CWS (1988) The oil palm (Elaeis guineensis Jacq.). Wiley, New York

3. Erwinsyah E (2008) Improvement of oil palm trunk properties using bioresin. Ph.D. thesis, Technische Universität Dresden, Germany

4. Sulaiman O, Salim N, Nordin NF, Hashim R, Ibbrahim M, Sato M (2012) The potential of oil palm trunk biomass as an alternative source for compressed wood. BioRes 7(2):2688-2706

5. H'ng PS, Chai LY, Chin KL, Tay PW, Eng HK, Wong HY, Wong WZ, Chow MJ, Chai EW (2013) Urea formaldehyde impregnated oil palm trunk as the core layer for three-layered board. Mater Des 50:457-462

6. Srivaro S (2014) Lightweight sandwich panel from oil palm wood core and rubberwood veneer faces. PhD Thesis, Walailak University, Thailand

7. Srivaro S, Matan N, Lam F (2015) Stiffness and strength of oil palm wood core sandwich panel under center point bending. Mater Des 84:154-162

8. Khalid I, Sulaiman O, Hashim R, Razak W, Jumhuri N, Rasat MSM (2015) Evaluation on layering effects and adhesive rates of laminated compressed composite panels made from oil palm (Elaeis guineensis) fronds. Mater Des 68:24-28

9. Rich PM (1987) Developmental anatomy of the stem of Welfia-Georgii, Iriartea-Gigantea, and other arborescent palmsimplications for mechanical support. Am J Bot 74:792-802
10. Fathi L (2014) Structural and mechanical properties of the wood from coconut palms, oil palms and date palms. PhD Thesis, University of Hamburg, Germany

11. Srivaro S, Rattanarat J, Noothong P (2018) Comparison of the anatomical characteristics and physical and mechanical properties of oil palm and bamboo trunks. J Wood Sci 64(3):186-192

12. Lim SC, Khoo KC (1986) Characteristics of oil palm trunk and its potential utilization. The Malaysian Forester 49(1):3-21

13. Haslett AN (1990) Suitability of oil palm trunk for timber uses. J Trop For Sci 2(3):43-51

14. Gan KS, Choo KT, Lim SC (2001) Basic density and moisture content distributions in 30-years-old oil palm (Elaeis guineensis) stems. J Trop For Prod 7(2):184-191

15. Walker JCF, Butterfield BG, Harris JM, Langrish TAG, Uprichard JM (1993) Primary wood processing. Chapman and Hall, New York

16. ASTM D143 (2009) Standard test methods for small clear specimens of timber. ASTM international, USA

17. Killmann W, Koh MP (1988) Oil palm stem densification using ammonia treatment: a preliminary study. J Trop For Sci 1(1):1-10

18. Ratnasingam J, Ma TP, Manikam M, Farrokhpayam SR (2008) Evaluating the machining characteristics of oil palm lumber. Asian J Appl Sci 1(4):334-340

19. Kretschmann DE (2010) Mechanical properties of wood. In: Ross RJ (ed) Wood handbook: wood as an engineering material. Forest product laboratory, Madison

20. Omar NS, Bakar ES, Jalil NM, Tahir PM, Yunus WMZW (2011) Distribution of oil palm starch for different levels and portions of oil palm trunk. Wood Res J 2(2):73-77

21. Bodig J, Jayne BA (1982) Mechanics of wood and wood composites. Van Nostrand Reinhold Company Inc, New York

22. Glass SV, Zelinka SL (2010) Moisture relations and physical properties of wood. In: Ross RJ (ed) Wood handbook-Wood as an engineering material. Forest product laboratory, Madison

23. Rich PM (1987) Mechanical structure of the stem of arborescent palms. Bot Gaz 148:42-50

24. BS EN 338 (2016) Structural timber-strength classes. European committee for standardization, Brussels 